\title{
Multitherapy - therapy techniques developed by Lou de Olivier
}

\author{
Lou de Olivier \\ University of Sao Paulo, Brazil
}

The multitherapy began to be drawn from 1980, improved to 2001 when it was first published, with repercussions in Brazil, Portugal and England. In 2004, Lou de Olivier came to present herself as educational Psychologist and Multitherapist in various Radio and TV stations and continued to publish articles in printed magazines and electronic newspapers in Brazil and Europe holding this name. In 2007, the "Psychology Brazil" magazine published a comprehensive report entitled "Therapist of Multiple Possibilities" having multitherapy technique been well explained in this article was the newsstands in June / 2007 under number 42, year 5 .

From this publication, many other occured in Brazil and Europe describing the technique developed by Lou de Olivier. Among recent publications are published in Dossier magazine "Psyche" 81, year VI - September 2012 and the book "Behaviour and Learning Disorders" describing multitherapy, both by Lou de Olivier

\section{Multitherapy, what is it?}

Originally titled multitherapy, have been very plagiarized and widespread wrongly received the subtitled Multiple Therapies: Therapeutic Technique developed by Lou de Olivier (pen name of Ana Lourdes de Oliveira) in order to promote an overall multi restructuring providing the individual balance in all aspects a mixture of technical areas and makes only multitherapy and effective in different treatments in that each patient is the sole, adapting the method to each event and monitoring the evolution of each frame individually. And, in all cases, balances / rebalances the patient in all aspects overall shape (multidirectional) and definitive.

\section{The main areas and techniques that make up the mul- titherapy}

Musical Therapy Psycho Analysis, Psycho Pedagogy, Art Therapy, Neuro Psychology, Behaviour Medicine and Fine Arts. Inside these areas, we use, in the begin, conventional therapies (interview/ anamnesis/ tests and others). From this, we use Psycho Drama, Therapeutic Theater, Poetry and creations, workshop and analysis in drawing and painting, dramatic games, several games, sounds and rhytms, body expression, relax in many levels, developments and others.

Remembering that in each treatment, is a series of skills adapted to the case to be treated. In special cases, Multitherapy has own resources, which drives the patient to a treatment, different of all others, with excellent results. Multitherapy follows the holism philosophy (Greek: holos, all) which, in therapeutic terms means that the man is an undivisible being, which cannot be understood throughout a separate analysis by his different parts, being, so, analysed and treated under various angles (biological, mental, psychologic, energetic - considering energetic as a mental condition of brain electricity emission). But, Multitherapy goes so far beyond this, it reunites very serious areas mentioned above -and aims to treat each individual as unique, adapting the treatment to each case, in a taylor-made (handcrafted) treatment, reaching so a high-level degree of control and cure to several disturbs, treated in the present day as "incurably".

ATTENTION: Multitherapy want neither advises interruption or denial of drug use. Even in very severe cases which require medication, the multitherapy can and should be associated with neurological / psychiatric treatment.

Multitherapist Lou de Olivier researches, publishes articles and books (and offer treatments) to Learning Disorders, (Dyslexia, Dysgraphy, etc) behavioral disorders (Obsessive Compulsive Disorder / Tourette, drug addiction, etc.), family disorders (domestic violence, therapies for couples, etc.)

\section{Differential: multitherapy X Multi disciplinary}

In some countries like Brazil, there is a misunderstanding in relation to the treatment of disfunctions/ disorders. It is often advised the Multidisciplinary treatment as the only alternative. Multidisciplinary, it is a joint united professionals for the same treatment. Then, speech therapist, psychologist, educational psychologist, neurologist and / or psychiatrist and other professionals working in the same clinic and can simultaneously meet the same patient. This type of treatment works, but it depends on full integration among professionals to apply techniques compatible and not divergent and also mean many sessions for the patient, as each professional individually meets in their sessions. Attempting to join more than two professionals in one session would be unproductive and unworkable in all aspects. Therefore, multidisciplinary treatment involves many sessions with various professionals. This is Multidisciplinary

Multitherapy is a technique that involves various areas and techniques and is applied by a professional one highly qualified in various therapeutic areas and able to apply the various features of multitherapy and tailor each treatment to each patient handmade, unique and subsumed. In very severe cases that require medication, the Multitherapist can and should work together with a Neurologist and / or psychiatrist in some cases may include treatment with Physiotherapist

Correspondence to: Lou de Olivier, University of Sao Paulo, Brazil, E-mail: louevoce@loudeolivier.com

Received: October 08, 2016; Accepted: October 15, 2016; Published: October 20, 2016 
or psychomotor. However the latter should only be necessary in cases of accidents or limitations that impair physical movements and require physical rehabilitation exercises.

\section{Multitherapy treating obsessive compulsive disorder}

Although cognitive behavioral therapy be considered the best choice (there are studies that hard claim therapy as first choice). in the treatment of Obsessive Compulsive Disorder (there are reports to be more effective than pharmacological interventions, with improvement for long periods of time and low relapse rates), in fact, few people has benefits from this technique, due to the high cost and is considerated

The multitherapy, besides behavioral therapy encompasses many techniques for various therapies, and which can be adapted to each particular case. This accelerates and improves the results of treatment not only of Obsessive-Compulsive Disorder, but several other disorders.

Remember that this treatment does not relieve the psychiatric support, especially in severe cases. However multitherapy can be great combined with drug treatment. For purposes of testing and evidence were attended by me, thirty patients, one from France, one from England, five of Portugal and the other twenty-three from Brazil. All had significant improvements and results were published in the book "Learning and Behavior Disorders - truths that no one published" - in 2003.

\section{Multitherapy as an allied in the treatment of dyslexia}

Many years ago, researchers insists on showing Dyslexia with genetic/hereditary cause, which requires continuous treatment. After many years of advocacy on the theme Dyslexia Acquired, Lou de Olivier can say that dyslexia can also be acquired by an accident (anoxia /hypoxia, stroke among others), it is now official for years.

What little or nothing is disclosed it is that most of the symptoms attributed to the Dyslexia is actually comorbidities that arise not always while Dyslexia, in most cases, co-morbidity arises after some time of diagnosis and treatment inadequate, instead of regress, Dyslexia is aggravated by comorbidities that would not exist if the case had correct diagnosis and effective treatment.

This is where the multitherapy, created by me, differs and acts more effectively in that it detects the actual symptoms of the patient and is broadly developing its creativity, memory and enabling a new way of learning.

\section{The multitherapy as an allied in social and behavioral education of autistic}

The Autism treatment proposed by multitherapy is old. It began in 1985 when Lou attended university extension in music therapy, shortly after graduating in Arts Education (Visual Arts) and become Bachelor of Performing Arts.

In college, in music therapy, taught the sounds and rhythms were great hope of communication with the brains of Autistic and Lou not only confirmed this in practice as developed a more evolved form combining music therapy with dance, theater, design and allying with technical psychological, studying for years in parallel, thereby achieving excellent results in the treatment of autistic and Down Syndrome realizing be possible to treat many diseases and disorders that conventional medicine was as "hopeless cases".
So was born the multitherapy with Lou Olivier (Ana Lourdes de Oliveira) and its Precursor, and at first called it "Psicoarte" then "Psiconeuroarte" by encompass psychological, neurological and artistic fields. At sequence, thought that multitherapy better define its creation.

The multitherapy seeks to address not only autism but hyperlexia that in some cases, is itself also of Autism and treat cases in which the mental retardation prevents learning. Milder cases usually have a responsive feel. Severe cases may not have a rapid response, but also in the long term, show improvements.

\section{About autism}

In the brain considered normal stimuli come through all the sensory pathways: sight, hearing, smell, taste and touch (five senses). And now already considered an area of balance as a possible sixth sense very far from the esoteric sixth sense, this is located in a part of the brain to the next channel that takes the sound to recognize the brain, so to speak. The inner ear / maze consists of two systems, the cochlear (sensory organ responsible for decoding the sounds) and vestibular (semicircular are saccule and utricle channels that inform the central nervous system about the position and movement of the head).

\section{The sound}

The sound stimulus that actually is a vibration, is captured and encoded in the cochlea and transmitted to the brain by the auditory nerve. In the brain, groups of specialized neurons (nuclei), Decode vibration taking it as a message conveyed to reach the auditory cortex. To get the message is as faithful as possible to the original stimulus, but it should be understood that come a way to get to the point of understanding.

The sound is picked up by the outer ear, the middle ear amplified and transmitted to the inner ear where the cochlea transform sound vibrations into nerve message.

\section{The vision}

The retina, at the posterior part of the eye, encodes the light (light stimuli). The visual messages pass and blind the optic nerve to the brain in a very detailed fashion (intensity of light, colors, sizes, etc.). This information is processed and end in the visual area of the occipital cortex, where is the perception. The summary is that, in the brain, different centers analyze stimuli and messages and decodes producing the perception in the cortex level.

In autism this does not occur or, if it occurs, is disorderly or unconventionally. Therefore, there is a failure of perception and communication in autistic individuals. The multitherapy offers techniques that supply this deficiency in the reception of stimuli. In many cases, it can penetrate into the world of autism, awakening sensitivity, creativity, and increased perception of the external world.

Uses music therapy continuously and original, not the distorted way that is offered today with Music being used AS THERAPY in multitherapy the technique is used in the original form with sounds and specific rhythms that suit every brain and stimulate learning and awakening.

\section{Before the treatment with multitherapy there are basi- cally two results}

Very severe cases are ameliorated more quickly and efficiently than treatments used today; Milder cases are resolved, usually with 
very positive results, especially in stimulating speech, hearing and development of artistic creativity.

\section{References}

1. Lou de Olivier (2013) Disorders of behavior and learning disorders.Publisher WAK, Rio de Janeiro - RJ.

2. Lou de Olivier. Educational Psychology and Art Therapy - Theory and practice in use in clinics and schools, Olivier Lou author. currently in third edition, Publisher WAK Rio de Janeiro - RJ.

3. Lou de Olivier (2003) Disorders of learning / behavior - truths that no one published now out of print since gave rise to the two above mentioned books and was not reissued.

4. Monograph perinatal anoxia generating dyslexia, dysgraphia and other significant disorders of learning, 1996/1997.
5. Lou de Olivier(2013) Dossier perinatal anoxia and acquired dyslexia. Psyche Magazine 90, EditoraEscala.

6. Lou de Olivier (2013) Article Dyslexia. Senses Magazine issue 74EditoraEscala.

7. Interview with Olivier Lou for the magazine Psychology Brazil, Issue 42, June / July 2007 Publisher Criarp.

8. Lou de OlivierArticle Dyslexia: exact definition of the disorder. Published in various print and electronic newspapers between 1996 and 2000, several publishers.

9. Lou de Olivierpublished articles, dossiers, participated in interviews on radio and television talking about Multi Therapy, Aacquired Dyslexia theme, and related topics (learning disorders, behavioral disorders, family disorders) and Also disclosing my innovative technique Multitherapy in between 1995 and 2013.

10. Multi Therapy interviews [Crossref]

11. Published articles and dossiers by Lou de Olivier [Crossref]

Copyright: $\odot 2016$ Olivier L. This is an open-access article distributed under the terms of the Creative Commons Attribution License, which permits unrestricted use, distribution, and reproduction in any medium, provided the original author and source are credited. 